\title{
The Employer-Employee and Teacher-Student Communication
}

\author{
Md. Ismail Khan
}

On constructive characteristics of employer-employee communication, Blanchard and Johnson's The One Minute Manager is particularly adaptable to teaching. Effective managers are those who manage themselves and the people they work with so that both the organization and the people profit from their presence. Similarly, effective teachers are those whose method of teaching benefit the teachers, the learner, the teaching setting (e.g., hospital ward or office), and the learner's future patients. The One Minute Manager offers three "secrets" of effective management that are equally applicable to effective medical teaching.

Me. first secret: Clarifying the Learning Objectives It proposes that the employers should help employees understand exactly what their responsibilities are and exactly what performance standards are necessary to meet those responsibilities. This proposal is directly applicable to Skeff's objective1 that the physician teachers clearly communicate the goals of teaching and learning.

The second secret: Communicating Positive Feedback

It advises employers to make sure, "in no uncertain times", that the employee understands when he is doing something well. As Blanchard and Johnson put it, "Catch them doing something right. " Most teachers are fairly good at giving positive feedback to learners eventually; however, the correct time to give it is immediately after a learner has performed well. Positive feedback is relatively easy to give in the presence of the patient, other health care personnel, or students.

The third secret: Communicating Negative Feedback This tells the employers to ensure that the employee understands when he is doing something wrong. Teachers generally do not want to be "bad persons" and are usually uncomfortable giving negative feedback. Unfortunately long time after the unmentioned error has occurred the student or resident

Dr. Md. Ismail Khan

Professor of Pharmacology DMC. Dhaka

Correspondence

Dr. Md. Ismail Khan

Professor of Pharmacology DMC, Dhaka is shocked at receiving a bad evaluation, and rightly so. Physician teacher must remember that medical teaching is a huge responsibility. Balanced negative feedback is a critical part of that responsibility.

Many physician teachers think that their only role as $\mathrm{s}$ teacher is to be a reservoir of knowledge with information flowing randomly toward students Expertise is not enough for good teaching: medica knowledge is necessary, but not sufficient condition to guarantee good teaching. Teaching is like coaching it that the aim to maximize another person's performance. The best teachers, like coaches, no only instruct, they inspire. J. Michael Bishop, c professor of Microbiology and Immunology at the University of California, San Fransisco (and winner of the Nobel Prize in Medicine) states that the three purposes and priorities of teaching are, "First to inspire. Second to challenge. Third, and only third, to impart information ${ }^{2,3}$ There is plenty of evidence that students respond much more enthusiastically to teachers who seem genuinely interested and committed to helping them learn ${ }^{4}$.

\section{Reference:}

1. Blanchard K, Johnson S. The One-Minute Manager, New York: William Morrow \& Co, 1982

2. Skeff KM. Assessment by attending physicians of a seminar method to improve clinical teaching. J Med Educ 59: 944-955, 198^

3. Whitman N, Schwenk TL. The Physician As Teacher, 2nd Ed, Whitman Associates, Salt Lake City: University of Utah School of Medicine,23, 1997

4. Tiberius RG et al. The influence of student evaluative feedbac on the improvement of clinical teaching, J Higher Educ 60: 665-67! 1989 